\title{
Three-Dimensional Modeling and Analysis of a Porous Thermal Energy Storage System
}

\author{
N.B. Khedher ${ }^{1}$ and S.B. Nasrallah ${ }^{2}$ \\ ${ }^{1,2}$ Université de Monastir, École Nationale d'Ingénieurs de Monastir, Laboratoire d'Études des Systèmes Thermiques \\ et Énergétiques LESTE, Avenue Ibn El Jazzar 5019, Monastir, TUNISIE \\ Email: nidhal.ben.khedher@gmail.com
}

(Received January 8, 2009; accepted September 6, 2009)

\begin{abstract}
The objective of this study is to analyze the behavior of an energy storage system which is made of a horizontal channel crossed by a fluid and whose walls contain an unsaturated porous medium. We developed a threedimensional model to study the two processes: thermal energy charging and thermal energy discharging. The coupled and highly non linear nature of the transport equations that govern the heat and mass transfer inside unsaturated medium were discretized by control volume finite element method (CVFEM). The resulted system of algebraic equations was solved by the Bi-Conjugate Gradient Stabilized iterative solver. Results concerning the influence of the initial liquid saturation on the rate of charged and discharged thermal energy are presented and analyzed.
\end{abstract}

Keywords: CVFEM, unsaturated porous medium, saturation effect, Whitaker, phase change, evaporation

\section{NOMENCLATURE}

$\mathrm{C}_{\mathrm{p}} \quad$ constant pressure specific heat $[\mathrm{J} /(\mathrm{Kg} . \mathrm{K})]$

$\mathrm{C}_{\mathrm{v}} \quad$ vapor concentration

D diffusion coefficient $\left[\mathrm{m}^{2} / \mathrm{s}\right]$

g gravitational constant $\left[\mathrm{m} / \mathrm{s}^{2}\right]$

$\mathrm{h}_{\mathrm{t}} \quad$ local coefficient of heat transfer $\left[\mathrm{W} /\left(\mathrm{m}^{2} . \mathrm{K}\right)\right]$

$\mathrm{K} \quad$ Intrinsic permeability $\left[\mathrm{m}^{2}\right]$

ly porous layer width

Ly system width

$\dot{\mathrm{m}} \quad$ Water evaporation mass rate $[\mathrm{Kg} / \mathrm{s}]$

M molar mass

$\mathrm{P} \quad$ pressure [Pa]

$\mathrm{P}_{\mathrm{c}} \quad$ capillary pressure $[\mathrm{Pa}]$

Q thermal energy exchanged $\left[\mathrm{W} / \mathrm{m}^{2}\right]$

$\mathrm{R} \quad$ universal gas constant $[\mathrm{J} /($ mole.K) $]$

$\mathrm{Re} \quad$ Reynolds Number

$\mathrm{S} \quad$ liquid saturation [\%]

$\overline{\mathrm{T}} \quad$ Average temperature $[\mathrm{K}]$

$\mathrm{T}_{0} \quad$ initial temperature $[\mathrm{K}]$

$\mathrm{T}_{\mathrm{m}, \mathrm{ex}} \quad$ mean exit temperature value $[\mathrm{K}]$

$\mathrm{t}$ time [s]

$\mathrm{U} \quad$ velocity $[\mathrm{m} / \mathrm{s}]$

$\mathrm{X}$ moisture content
$\Delta H_{\text {ap }} \quad$ Vaporisation latent heat $[\mathrm{J} / \mathrm{Kg}]$

$\Delta \mathrm{t} \quad$ time step

Greek symbols

$\varepsilon \quad$ Porosity

$\lambda \quad$ Thermal conductivity [W/(m.K)]

$\mu \quad$ Dynamic viscosity [N.s $\left./ \mathrm{m}^{2}\right]$

$\rho \quad$ Density $\left[\mathrm{Kg} / \mathrm{m}^{3}\right]$

$\sigma \quad$ Surface tension $[\mathrm{N} / \mathrm{m}]$

\section{Subscripts}

a air

eff effective

ex exit

g gas

in inlet

1 liquid

s solid

v vapor

$\mathrm{x}, \mathrm{y}, \mathrm{z} \quad$ Cartesian coordinates

$0 \quad$ initial 


\section{INTRODUCTION}

The growing use of energy which is mainly derived from fossil fuel and wood fuel has caused serious environmental and ecological problems. These imply that development and utilization of renewable energy is the best idea. But the major drawback of the renewable energy is that it is not usually available: for example the solar energy doesn't exist at night. In order to overcome this problem, the renewable energy should be stored. So it is important to develop thermal storage systems (TES).

Thermal storage systems have been relevant, especially in solar thermal applications (Fath, 1998). Basically, there are three methods of storing thermal energy: sensible, latent and thermo-chemical heat storages. Although the sensible heat storage (SHS) system is simple and a well-developed technology, this type of storage is the least efficient method of storage system because of low heat storage capacity. The latent heat storage (LHS) system employing phase change material $(\mathrm{PCM})$ as storage medium has been widely noticed as an effective way due to its advantages of high energy storage density and its isothermal operating characteristics during the charging and discharging processes. However, practical difficulties usually arise in applying the latent melting/solidification heat method due to its low thermal conductivity, density change, and the poor heat transfer rate during heat storage and recovery processes. The main reason of the low heat transfer rate is that during phase change the solid-liquid interface moves away from the heat transfer surface. Moreover the surface heat fluxes decreases due to the increasing thermal resistance of the growing layer thickness of the molten/solidified medium.

Over the last decade, a lot of research work has been performed to examine the thermal behavior and performance of various TES systems. Abhat et al. (1983) gave a useful classification of the substances used for TES. Among the most thorough references related with phase change materials, one can cite Zalba et al. (2003) and Dincer et al. (2002). These studies contain a detailed review of the types of material which have been used, their classification and characteristics.

Recently, Anica et al. (2006) have analyzed the heat transfer in water-paraffin shell-and-tube latent thermal storage unit. Lacroix (1993) and Hassan (1994) have studied the same kind of storage system. The heat transfer in storage systems is a conjugate problem of transient forced convective heat transfer between the flowing fluid and the wall and heat conduction through the wall. There are several methods to enhance the heat transfer in a TES system. The use of finned tubes with different configurations has been proposed by several searchers as an efficient mean to improve the charge /discharge capacity (Padmanabhan et al. 1986, Verlaj et al. 1997, Ismail et al. 2001). Ettouney et al. (2004) studied the heat transfer improvement by the use of metal screens/spheres placed inside the phase change material (PCM).

Other heat transfer enhancement technique is to embed the PCM in a metal matrix structure (Tong et al. 1996,
Verlaj et al. 1999, Jyan et al. 2003). Although the addition of a porous medium adds some extra complexities, it ameliorates obviously the heat transfer inside the TES systems. In the present paper, we have numerically studied the three-dimensional latent heat storage inside porous-medium. A serial of numerical calculations have been performed in order to analyze the transient heat transfer during charging and discharging energy processes. Influences of the initial liquid saturation and the porous layer thickness on the stored and recovered energy have been studied.

\section{Modeling}

\subsection{Mathematical Model}

The system considered in this work is a rectangular channel bounded by porous layer composed of:

- An inert and rigid solid phase,

- A liquid phase (pure water),

- A gaseous phase which contains both air and water vapor.

A forced fully developed flow crosses this channel. The porous layers are impervious and they do not exchange mass with fluid flow.

\subsection{Governing Equations}

In this work we focus on the heat exchange between the fluid flow and the porous layer.

So our system can be divided in two regions: fluid region and porous channel region.

\subsubsection{Fluid region}

The fluid is assumed to be Newtonian with uniform properties. The flow is considered to be laminar incompressible unidirectional and dynamically developed. The velocity profile of the fluid flow is given by:

$U(y)=6 U_{\text {moy }} \frac{\left(y-l_{y}\right)\left(L_{y}-y\right)}{\left(L_{y}-l_{y}\right)^{2}} \quad 1_{\mathrm{y}} \leq y \leq L_{y}$

where $U_{\text {moy }}$ is the mean value of the velocity.

The heat transfer is governed by the single-phase energy equation.

$$
\begin{aligned}
& \frac{\partial}{\partial t}\left[\begin{array}{lll}
\rho & c_{p f} T
\end{array}\right]+\operatorname{div}\left[\rho c_{p f} \vec{V}_{f} T\right]= \\
& \operatorname{div}\left[\lambda_{f} \underset{\operatorname{grad} T}{\rightarrow}\right]
\end{aligned}
$$

\subsubsection{Porous Channel}

Inspiring by Whitaker theory (Whitakar, 1977), a mathematical model governing heat and mass transfer is established for the unsaturated porous media. In order to obtain a closed set of governing macroscopic equations, the following assumptions are made: - The porous layer is homogenous and isotropic.

- The solid, liquid and gas phases are in local thermodynamic equilibrium. 
- The compression-work and viscous dissipation are negligible.

- The gas-phase is ideal in the thermodynamic sense.

- The dispersion and tortuosity terms are interpreted as diffusion term.

Considering these assumptions, macroscopic equations governing heat and mass transfer in the porous layer are:

\subsubsection{Generalized Darcy's Law}

The average velocities of the liquid phase $\left(\overline{V_{l}}\right)$ and the gas phase $\left(\overline{V_{g}}\right)$ are obtained using Darcy's Law; which is generalized by using the concept of relative permeability, defined as the ratio between the effective permeability and the intrinsic permeability.

For the liquid phase:

$\overline{V_{l}}=-\frac{\mathrm{KK}_{1}}{\mu_{1}}\left[\nabla\left({\overline{\mathrm{P}_{\mathrm{g}}}}^{\mathrm{g}}-P_{c}\right)-{\overline{\rho_{1}}}_{\mathrm{g}}^{\mathrm{g}}\right]$

with $P_{c}={\overline{P_{g}}}^{g}-{\overline{P_{l}}}^{l}$

For the gas phase, without taking into consideration the gravitational effect, we have:

$\overline{V_{g}}=-\frac{K K_{g}}{\mu_{g}} \nabla{\overline{P_{g}}}^{g}$

where $\mathrm{Pc}$ is the capillary pressure (Scheidegger, 1974).

\subsubsection{Mass conservation equations}

- Liquid phase

Assuming that liquid density is constant, the mass conservation equation of the liquid phase is:

$\frac{\partial X}{\partial t}+\nabla\left(\overline{\mathrm{V}_{1}}\right)=-\frac{\dot{m}}{\rho_{1}}$

where $\dot{m}$ is the mass rate of evaporation and $\varepsilon_{l}$ is the volume fraction of liquid phase.

- Gas phase

For this phase the average density is not constant. In this case, the mass conservation equation of the gas phase is given by:

$\frac{\partial \overline{\rho_{g}}}{\partial t}+\nabla\left(\bar{\rho}_{g}^{g} \overline{V_{g}}\right)=\dot{m}$

where $\bar{\rho}_{g}^{g}$ is the intrinsic average density of the gas phase. This phase is considered as an ideal mixture of perfect gases.

- Vapor phase:

$$
\begin{aligned}
& \frac{\partial \overline{\rho_{\mathrm{v}}}}{\partial t}+\nabla\left(\bar{\rho}_{\mathrm{v}}^{g} \overline{V_{\mathrm{v}}}\right)=\dot{m} \\
& \bar{\rho}_{v}^{g} \bar{V}_{v}=\bar{\rho}_{v}^{g} \bar{V}_{g}-\bar{\rho}_{\mathrm{g}} \mathrm{D}_{\mathrm{eff}} \nabla\left(\overline{\rho_{\mathrm{v}}} /{\overline{\rho_{\mathrm{g}}}}_{\mathrm{g}}\right)
\end{aligned}
$$

$D_{\text {eff }}$ represents the coefficient of the effective diffusion of the vapor in the porous medium. This coefficient takes into account the resistance to the diffusion due to tortuosity and the effects of constriction.

\subsubsection{Energy conservation equation}

$\frac{\partial}{\partial t}\left(\overline{\rho \mathrm{C}_{\mathrm{p}}} \overline{\mathrm{T}}\right)+\operatorname{div} \cdot\left[\left(\overline{\rho_{1}} \mathrm{C}_{\mathrm{pl}} \overline{\mathrm{v}_{1}}+\sum_{\mathrm{k}=\mathrm{a}, \mathrm{v}} \overline{\rho_{\mathrm{k}}} \mathrm{C}_{\mathrm{pk}} \overline{\mathrm{v}_{\mathrm{k}}}\right) \bar{T}\right]$ $=\nabla\left(\lambda_{\mathrm{eff}} \cdot \overline{\nabla \mathrm{T}}\right)-\Delta H_{\mathrm{vap}} \cdot \dot{m}_{\mathrm{v}}$

$\Delta \mathrm{H}_{\text {vap }}$ is the latent heat of vaporization at temperature $\mathrm{T}(\mathrm{K})$ :

$\Delta \mathrm{H}_{\mathrm{vap}}=\Delta \mathrm{H}_{\mathrm{vap}}^{\circ}+\left(\mathrm{C}_{\mathrm{pv}}-\mathrm{C}_{\mathrm{pl}}\right) \overline{\mathrm{T}}$, where $\Delta \mathrm{H}_{\mathrm{vap}}^{\circ}$ is the latent heat of vaporization at $\mathrm{T}=0 \mathrm{~K}$.

$\lambda_{\text {eff }}$ and $\overline{\rho C_{p}}$ are, respectively, the effective thermal conductivity and the constant pressure heat capacity of the porous medium, $\overline{\rho C_{p}}$ is given by:

$\overline{\rho C_{p}}=\bar{\rho}_{s} C_{p s}+\bar{\rho}_{1} C_{p l}+\bar{\rho}_{\mathrm{a}} C_{p a}+\bar{\rho}_{\mathrm{v}} C_{p v}$,

where $\quad \bar{\rho}_{\mathrm{s}} \mathrm{C}_{\mathrm{ps}}, \quad \bar{\rho}_{\mathrm{l}} \mathrm{C}_{\mathrm{pl}}, \quad \bar{\rho}_{\mathrm{v}} \mathrm{C}_{\mathrm{pv}}$ and $\bar{\rho}_{\mathrm{a}} \mathrm{C}_{\mathrm{pa}}$ are, respectively, the mass heat capacities of the solid, liquid, vapor and air.

\subsubsection{Thermodynamic relations}

The partial pressure of the vapor is equal to its equilibrium pressure: $\mathrm{Pv}=\operatorname{Pveq}(\mathrm{T}, \mathrm{S}), \mathrm{S}$ is the liquid saturation defined by $S=\frac{X}{\varepsilon}$

The gaseous phase is assumed to be an ideal mixture of perfect gases:

$\overline{\mathrm{P}}_{\mathrm{i}}=\frac{\rho_{\mathrm{i}}}{\mathrm{M}_{\mathrm{i}}} \mathrm{R} \overline{\mathrm{T}} ; \mathrm{i}=\mathrm{a}, \mathrm{v}$

$\overline{\mathrm{P}}_{\mathrm{g}}=\overline{\mathrm{P}}_{\mathrm{a}}+\overline{\mathrm{P}}_{\mathrm{v}}$

$\bar{\rho}_{\mathrm{g}}=\bar{\rho}_{\mathrm{a}}+\bar{\rho}_{\mathrm{v}}$

\subsection{Boundary and Initial Conditions}

Initially, the temperature, the gas pressure and liquid saturation are uniform in the porous medium.

$\bar{T}(x, y, z, t=0)=T_{0}, \overline{P_{g}^{g}}(x, y, z, t=0)=P_{g 0}$

$\bar{S}(x, y, z, t=0)=S_{0}$

At the inlet face $(\mathrm{x}=0)$

- Fluid region

$T_{f}(x=0, y, z, t)=T_{i n} 1_{\mathrm{y}} \leq y \leq L_{y}$

-Porous region 


$$
\begin{aligned}
& \left(0 \leq y \leq 1_{\mathrm{y}}\right) \text { and }\left(\mathrm{L}_{\mathrm{y}}<y<L_{y}+l y\right) \\
& \frac{\partial \bar{T}}{\partial x}=0, \quad\left[\left\langle\rho_{\mathrm{v}}\right\rangle^{\mathrm{g}}\left\langle\overrightarrow{\mathrm{V}_{\mathrm{v}}}\right\rangle+\rho_{1}\left\langle\overrightarrow{\mathrm{V}_{1}}\right\rangle\right] \cdot \overrightarrow{\mathrm{n}_{\mathrm{x}}}=0 \\
& {\left[\frac{\partial\left\langle P_{g}\right\rangle^{g}}{\partial x}\right]=0}
\end{aligned}
$$

At the exit face $(\mathrm{x}=\mathrm{Lx})$

- Fluid region

$$
\frac{\partial T_{f}}{\partial x}=0
$$

- Porous region

$$
\begin{aligned}
& \frac{\partial \bar{T}}{\partial x}=0,\left[\left\langle\rho_{\mathrm{v}}\right\rangle^{\mathrm{g}}\left\langle\overrightarrow{\mathrm{V}_{\mathrm{v}}}\right\rangle+\rho_{1}\left\langle\overrightarrow{\mathrm{V}_{\mathrm{l}}}\right\rangle\right] \cdot \overrightarrow{\mathrm{n}_{\mathrm{x}}}=0 \\
& ,\left[\frac{\partial\left\langle P_{\mathrm{g}}\right\rangle^{g}}{\partial x}\right]=0
\end{aligned}
$$

On the adiabatic and impervious sides, the mass and heat fluxes are equal to zero.

At $\mathrm{z}=0$ and $\mathrm{z}=\mathrm{Lz}$

$$
\begin{aligned}
& \frac{\partial \bar{T}}{\partial z}=0,\left[\left\langle\rho_{\mathrm{v}}\right\rangle^{\mathrm{g}}\left\langle\overrightarrow{\mathrm{V}_{\mathrm{v}}}\right\rangle+\rho_{1}\left\langle\overrightarrow{\mathrm{V}_{\mathrm{l}}}\right\rangle\right] \cdot \overrightarrow{\mathrm{n}_{\mathrm{z}}}=0, \\
& {\left[\frac{\partial\left\langle P_{g}\right\rangle^{g}}{\partial z}\right]=0}
\end{aligned}
$$

At $y=0$ (the lower face of the porous medium) and at $\mathrm{y}=\mathrm{Ly}+2 \mathrm{ly}$ (the upper face of the porous medium)

$$
\begin{aligned}
& \frac{\partial \bar{T}}{\partial y}=0,\left[\left\langle\rho_{\mathrm{v}}\right\rangle^{\mathrm{g}}\left\langle\overrightarrow{\mathrm{V}_{\mathrm{v}}}\right\rangle+\rho_{1}\left\langle\overrightarrow{\mathrm{V}_{\mathrm{l}}}\right\rangle\right] \cdot \overrightarrow{\mathrm{n}_{\mathrm{y}}}=0, \\
& {\left[\frac{\partial\left\langle P_{\mathrm{g}}\right\rangle^{g}}{\partial y}\right]=0}
\end{aligned}
$$

At the wall separating pure fluid region and the porous medium ( $\mathrm{y}=\mathrm{ly}$ and $\mathrm{y}=\mathrm{Ly})$, the heat flux is continuous.

$$
\begin{aligned}
& \left.\lambda_{e f f} \frac{\partial \bar{T}}{\partial y}\right|_{y=l y}=-\left.\lambda_{f} \frac{\partial T_{f}}{\partial y}\right|_{y=l y} \\
& \left.\lambda_{e f f} \frac{\partial \bar{T}}{\partial y}\right|_{y=L y}=-\left.\lambda_{f} \frac{\partial T_{f}}{\partial y}\right|_{y=L y} \\
& {\left[\left\langle\rho_{\mathrm{v}}\right\rangle\left\langle\overrightarrow{\mathrm{V}_{\mathrm{v}}}\right\rangle+\rho_{1}\left\langle\overrightarrow{\mathrm{V}_{\mathrm{l}}}\right\rangle\right] \cdot \overrightarrow{\mathrm{n}_{\mathrm{y}}}=0\left[\frac{\partial\left\langle P_{g}\right\rangle^{g}}{\partial y}\right]=0}
\end{aligned}
$$

and $\bar{T}=T_{f} \quad$ for $\quad y=l y$ and $y=L y$

\section{NUMERICAL TrEatMENT}

The equations set, with initial and boundary conditions have been solved numerically using the control volume finite element method (CVFEM) (Balliga et al. 1980, Balliga et al. 1983, Saobas 1994, Omri et al. 1999). The advantages of this method are (i) It ensures the flux conservation (ii) the used control volumes present more faces, that makes it possible to avoid the numerical diffusion. (iii) The control volume is composed of triangular elements which improve the grid flexibility.

The 3D discretization of the physical domain repose on dividing the plane $(\mathrm{x}, \mathrm{y})$ into three-node triangular elements. Then the centroids of these elements are joined to the midpoints of the corresponding sides. This creates the polygonal control volumes around each node in the finite element grid. At this level the 3D discretization is similar to $2 \mathrm{D}$ one. But for the $3 \mathrm{D}$ discretization we complete the construction of the control volume by employing the finite-volume method along the third direction (z) (Fig. 2).

The governing equations cited before could be written in the following form:

$\frac{\partial\left(f_{1} \Phi\right)}{\partial t}+\operatorname{div}\left(\vec{J}_{\Phi}\right)=S_{\Phi}$

With the vector $\overrightarrow{\mathrm{J}}_{\Phi}$, representing combined convection and diffusion flux of the dependent variable $\Phi(\mathrm{T}, \mathrm{P}$, $\mathrm{TL})$ given by

$\overrightarrow{\mathrm{J}}_{\Phi}=f_{2} \vec{U} \Phi-\Gamma_{\Phi} \operatorname{grad} \Phi$

$\Gamma_{\Phi}, \vec{U}$ and $\quad S_{\Phi}$ are respectively diffusion coefficient, the velocity vector and the source term.

The control volume is composed of six sub-volumes $\Omega_{b}$ (Fig. 3) with equal sizes.

$$
\begin{aligned}
& \int_{t}^{t+\Delta t} \int_{V_{c}}\left(\frac{\partial\left(f_{1} \Phi\right)}{\partial t}+\operatorname{div} \vec{J}_{\Phi}-S_{\Phi}\right) d V_{c} d t= \\
& \int_{t}^{t+\Delta t} \sum_{\Omega_{b}} \int_{\Omega_{b}}\left(\frac{\partial\left(f_{1} \Phi\right)}{\partial t}+\operatorname{div} \vec{J}_{\Phi}-S_{\Phi}\right) d \Omega_{b} d t=0
\end{aligned}
$$

Instead of integrate over all sub-volumes; we work simply on one sub-volume $\Omega_{b}$.

The integration of Eq. (13) over the sub-volume $\left(\Omega_{b}\right)$, using the divergence theorem and the implicit procedure, leads to:

$$
\begin{aligned}
& \int_{\Omega_{b}} \frac{\left(f_{1} \Phi\right)^{n+1}-\left(f_{1} \Phi\right)^{n}}{\Delta t} d \Omega_{b}+\int_{\Gamma} \vec{J}_{\Phi}^{n+1} \cdot \vec{n} d \Gamma \\
& =\int_{\Omega_{b}} S_{\Phi}^{n+1} d \Omega_{b}
\end{aligned}
$$

where $\Delta t$ is the time step, the subscripts $n$ and $n+1$ refer to a previous instant $\mathrm{t}$ and the latest instant $\mathrm{t}+\Delta \mathrm{t}$, and $\vec{n}$ denotes the outward pointing normal vector on the control volume surface $\Gamma$. 
For the reason of simplification the control volume surface $\Gamma$ can be divided into simple surfaces with easily-determined normal vectors.

So the integration of the vector of flux over the control volume surface $\Gamma$ (Fig. 3) can be written in this way:

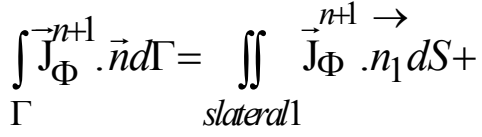

$$
\begin{aligned}
& \iint_{\text {slateral2 }} \overrightarrow{\mathrm{J}}_{\Phi}^{n+1} \cdot n_{2} d S+\iint_{\text {basel }} \overrightarrow{\mathrm{J}}_{\Phi}^{n+1} \cdot \bar{n}_{3} d S \\
& +\iint \overrightarrow{\mathrm{J}}_{\Phi}^{n+1} \cdot \overrightarrow{n_{4}} d S+[\mathrm{T}] \\
& \text { base } 2 \\
& {[T]=\iint_{\text {border1 }} \overrightarrow{\mathrm{J}}_{\Phi}^{n+1} \cdot \vec{n}_{b 1} d S+\iint_{\text {border2 }} \overrightarrow{\mathrm{J}}_{\Phi}^{n+1} \cdot \vec{n}_{\mathrm{b} 2} d S}
\end{aligned}
$$

For an interior node the term $[T]$ of all sub-volumes is equal to zero. Otherwise, we should take boundary conditions into account in order to calculate this term.

We have chosen a linear interpolation of $\Phi$ in order to calculate the flux term across the control volume faces. The resulting algebraic system from assembling the contributions of all sub-volumes has the following general form:

$$
A_{P} \Phi_{P}^{n+1}=\sum_{n b} A_{n b} \Phi_{n b}^{n+1}+B^{\Phi}
$$

The subscripts $\mathrm{P}$ and $\mathrm{nb}$ denote respectively the principal node and the neighboring nodes.

The resulting algebraic system has been solved iteratively by SSOR-preconditioned BICGSTAB (BiConjugate Gradient Stabilized) (Saad, 1996) algorithm which has been implemented in FORTRAN computer code.

\section{Results AND Discussions}

Heat transfer calculations between forced air flow and the porous medium were conducted for two cases discharging and charging processes. We have considered these two cases according to the initial temperature of the porous medium $\mathrm{T}_{0}$ and the inlet temperature of forced flow $T_{\text {in }}$ : the charging of thermal energy case $\left(\mathrm{T}_{0}<\mathrm{T}_{\text {in }}\right)$ and the discharging of stored energy case $\left(\mathrm{T}_{0}>\mathrm{T}_{\text {in }}\right)$. For each case we have determined the temperature profiles for the porous medium and the flowing fluid. We have calculated mean exiting temperature $\mathrm{T}_{\mathrm{m} \text {,ex }}$ of the forced air-flow at the outlet face, which is defined by:

$T_{\text {m,ex }}=\int_{\text {exit face }} \rho U T d S / \int_{\text {exit face }} \rho U d S$
Moreover we have determined the net thermal energy stored or discharged from the porous medium defined by:

$$
\begin{aligned}
& Q_{\text {net }}=Q_{\text {inlet }}-Q_{\text {outlet }}= \\
& \int_{\text {inlet face }} \rho_{f l} c_{f l} U T d S-\int_{\text {exit face }} \rho_{f l} c_{f l} U T d S
\end{aligned}
$$

The thermophysical properties of the fluids and the porous medium (brick) are shown in Appendix.

\subsection{The Case of Charging Thermal Energy}

The storage of thermal energy within the porous medium is done during the phase change of the liquid water which evaporates by receiving heat yielded by the flow of hot air circulating between the two porous plates.

The operating con qditions of the numerical simulation are depicted in the following table.

Table 1 operating conditions of the charging case

\begin{tabular}{|l|l|}
\hline Inlet temperature of the fluid flow $\mathrm{T}_{\text {in }}$ & $100^{\circ} \mathrm{C}$ \\
\hline Initial porous medium temperature $\mathrm{T}_{0}$ & $20^{\circ} \mathrm{C}$ \\
\hline Initial pressure gas $\mathrm{Pg}_{0}($ bar $)$ & 1 \\
\hline Liquid saturation & $50 \%$ \\
\hline Reynolds number $\mathrm{Re}$ & 500 \\
\hline
\end{tabular}

As shown in the Fig. 4 the mean exiting temperature of forced flow has a low value at the beginning then starts to increase to reach the inlet temperature value. This cooling of the air is caused by the temperature difference between the porous medium and the flowing fluid. The circulating air transfers the heat to the porous medium which is consequently heated. The stored heat causes the evaporation of the liquid existing inside the porous medium (Fig. 5). At the end of the storage process the whole medium stabilizes toward a uniform temperature equals to the inlet temperature (Fig. 6). From Fig. 5, we can notice that at the beginning the liquid saturation near the exchange face decreases because of the temperature gradient between the flowing fluid and the porous medium. Then it increases under capillarity effect to stabilize at the end. The behaviour of the liquid moisture content near the lower face is unlike the behaviour observed near the upper one. It increases slightly first because of the condensation of the steam diffused inside the porous medium by pressure and gravity effect. Then it decreases to reach a uniform saturation. The liquid evaporation causes an overpressure inside the porous medium (Fig. 7). The stored thermal energy (Fig. 8) inside the porous medium is an increasing curve. At the end of the storage period the temperatures of the porous medium and the flowing fluid become equal (Fig. 6).

As a consequence, no additional heat is transferred to the porous medium and the stored energy becomes constant. The Figs. 9, 10 and 11 show the temperature and the saturation fields for the porous medium at different instants of the charging period. 


\subsection{The Case of Dicharging Thermal Energy}

The operating conditions of the numerical simulation are depicted in the following table.

Table 2 operating conditions of discharging case

\begin{tabular}{|l|l|}
\hline Inlet temperature of the fluid flow $\mathrm{T}_{\text {in }}$ & $20^{\circ} \mathrm{C}$ \\
\hline Initial porous medium temperature $\mathrm{T}_{0}$ & $100^{\circ} \mathrm{C}$ \\
\hline Initial pressure gas $\mathrm{Pg}_{0}$ (bar) & 1.29 \\
\hline Liquid saturation & $40 \%$ \\
\hline Reynolds number $\mathrm{Re}$ & 500 \\
\hline
\end{tabular}

The discharging of energy occurs when the temperature of the circulating air is lower than the temperature of the porous medium. In this case the medium is initially hot since it stored heat during the charging phase. We have taken initial saturation equal to final saturation resulting from the storage phase. In the same way we have taken the initial gas pressure equal to the final one of the storage phase. Contrary to the previous case the flowing fluid gains the heat from the porous medium. The Fig. 12 shows that the temperature of the fluid increases from the inlet to reach greater value at the exit which is lower than the initial temperature of the porous medium. The previously stored heat is discharged by providing a heated air. Whereas the temperature of the porous medium decreases to reach the initial temperature of the flowing fluid. When the whole stored energy is released the flowing fluid regains its initial temperature. From Figs. 13 and 14 we can notice that the fall in the temperature of the stock is accompanied by a condensation of water. The liquid saturation near the exchange face increases rapidly at the beginning then it decreases to reach a uniform value at the end. The amount of the latent heat previously stored is greater than the amount of released one (Fig. 16). Since the liquid which was evaporated during the storage period, does not condense completely during the discharging process. This incomplete condensation can be justified by the high pressure value of the closed porous tank reached at the end of the charging period (Fig. 15). The Figs. 17, 18 and 19 show the temperature and the saturation fields for the porous medium at different instants of the discharging period.

\subsection{Influence of Initial Liquid Saturation}

Energy transport in a porous medium occurs by conduction in all of the phases as well as by convection with those phases which are able to move. Mass transport occurs within the voids of the medium. In an unsaturated state these voids are partially filled with a liquid, whereas the rest of the voids contains some gas. In our case, the liquid is water and the gas is air. Evaporation or condensation occurs at the interface between the water and the air so that the air is mixed with water vapor. A flow of the mixture of air and vapor may be caused by external forces, for instance, by an imposed pressure difference. The vapor will also move relative to the gas by diffusion from regions where the partial pressure of the vapor is higher to those where it is lower. The partial pressure of vapor at the interface to the liquid is determined by the sorption isotherm, which makes it dependent on moisture content as well as on temperature. In the same way the phenomenon of diffusion of gas depends on the coefficient of diffusion which is strongly related to liquid saturation. The flow of the liquid is caused by the external forces, like imposed differences in internal pressure, gravity, and forces, like the capillary forces, intermolecular forces translated by the phenomenon of diffusion of liquid resulting from the gradients of concentration. The dependence of the capillary forces and phenomenon of diffusion of saturation justifies the importance of the study of the effect of saturation on the rate of stored energy. A set of numerical calculations have been performed in order to evaluate the influence of the initial liquid saturation on the amounts of stored and recovered thermal energy during charging and discharging processes.

\subsection{Charging Case}

From Fig. 20 we can notice that the increase of initial liquid saturation always causes an increase in the rate of sensible stored energy what is obvious since by increasing saturation we raise the mass of the liquid where we will store heat. But the increase in initial liquid saturation does not always raise the rate of the stored latent heat (Fig. 20b). It is noticed that for liquid saturation higher than $50 \%$ the rate of stored latent energy starts by decreasing. We can also notice from Fig. 21 that initial saturation $50 \%$ corresponds to the greatest quantity of total heat possible to store. We can also remark the existence of a saturation of inversion from which the increase of saturation reduces the rate of the stored latent heat. From Fig. 22 we notice that the effective diffusion coefficient decreases when liquid saturation increases whereas the permeability is increasing according to saturation. From Fig. 23 we can notice that the capillary pressure is strongly influenced by saturation. The superposition of evolutions of these parameters enables us to identify the value of saturation $(\approx 50 \%)$ for which the phenomena of diffusion and capillarity have a significant effect and contribute together to store maximum energy.

If we take the extreme cases of saturation we can note that for weak saturations the permeability is low almost null and consequently the phenomenon of convection is negligible. For great saturations the coefficient of effective diffusion and the capillary pressure tend towards zero. Therefore the capillary forces and the phenomenon of diffusion are negligible. In this case the porous medium is isolated from the face of exchange by a gas film.

\subsection{Discharging Case}

The initial values of saturation taken for the discharging phase correspond to the values found at the end of the storage phase. We can observe from Fig. 24 that during the discharging an increase in initial saturation causes an increase in the discharged sensible energy and a reduction in the discharged latent energy. This result is justified by the fact that by increasing saturation we reduce the content of vapor which is initially hot. This vapor will condense by yielding heat towards the flow of air. we can notice that the most significant rate of total discharged heat is reached for the weakest initial 
saturation (Fig. 24c). Unlike the charging period, during this phase there is not a saturation of inversion.

\section{Conclusion}

Thermal energy storage system, composed of air flow and a channel formed by porous medium, has been analyzed in this paper. A mathematical model for threedimensional transient heat transfer between flowing fluid and porous medium has been presented. A computer code was developed using FORTRAN language based on the control-volume finite element method (CVFEM). Numerical predictions of transient heat transfer during charging and discharging processes have been analyzed. The influence of the initial liquid saturation has been studied. The employment of porous materials to store energy is quite efficient since the placement porous media enhance the heat transfer. This storage system can play the role of natural airconditioner by storing the daytime solar heat which will be utilized at nights or during cloudy periods. To supplement this study we can study the influence of other parameters such as the initial gas pressure, the nature of the liquid existing within the porous medium. In order to improve the efficiency of the storage system, it would be interesting, to carry out an analysis of the stock behavior during a continuous cycle chargingdischarging.

\section{REFERENCES}

Abhat, A. (1983). Low temperature latent heat thermal energy storage: heat storage materials. Solar Energy 30, 313-332.

Balliga, B.R., S.V. Patankar (1983). A control-volume finite element method for two-dimensional fluid flow and heat transfer. Numerical Heat Transfer 6, 245-6.

Balliga, B.R., S.V. Patankar (1980). A new finiteelement formulation for convection-diffusion problems. Numer Heat Transfer 3, 393-409.

Dincer, I., Rosen, M.A. (2002). Thermal Energy Storage Systems and Applications. John Wiley $\&$ Sons, Chichester (England).

Ettouney, H.M., I. Alatigi, M. Al-Sahali, S.A. Al-Ali (2004). Heat transfer enhancement by metal screens and metal spheres in phase change energy storage systems. Renewable Energy 29, 841-60.

Fath, H.E.S. (1998). Technical assessment of solar thermal energy storage technologies. Renewable Energy 14 (1) 35-40.

Hassan, A. (1994). Phase change material energy storage system employing palmitic acid. Solar energy 52 (2), 143-154.

Ismail, K.A.R., C.L.F. Alves, M.S. Modesto (2001). Numerical and experimental study on the solidification of PCM around a vertical axially finned isothermal cylinder. Applied Thermal Engineering 21 53-77.
Lacroix, M. (1993). Numerical simulation of a shelland-tube latent heat thermal energy storage unit. Solar Energy 50 (4), 357-367.

Omri, A. and S.B. Nasrallah (1999). Control volume finite element numerical simulation of mixed convection in an air-cooled cavity. Numerical Heat Transfer 36, 615-37.

Padmanabhan, P.V. and M.V. Krishna Muthy (1986). Outward phase change in a cylindrical annulus with axial fins on the inner tube. International Journal of Heat Mass Transfer 29 1855-1866.

Saad, Y. (1996). Iterative Methods for Sparse Linear Systems. PWS Publishing Company.

Saobas, H.J. and B.R. Balliga (1994). Collocated equal order control volume finite-element method for multidimensional, incompressible fluid flow, Part I: formulation. Numerical Heat Transfer B 26, 381407.

Scheidegger, A.E. (1974). The Physics of Flow Through Porous Media, $3 r d(E d)$. University of Toronto Press, Toronto.

Tong, X., J.A. Khan and M.R. Amin (1996). Enhancement of heat transfer by inserting a metal matrix into a phase change material. Numer. Heat Transfer part A 30, 125-141.

Trelles, J.P., J.J. Dufly (2003). Numerical simulation of porous latent heat thermal energy storage for thermoelectric cooling. Applied Thermal Engineering 23, 1647-1664.

Trp, A., K. Lenic and B. Frankovic (2006). Analysis of the influence of operating conditions and geometric parameters on heat transfer in waterparaffin shell-and-tube latent thermal energy storage unit. Applied Thermal Engineering 26, $1830-1839$

Verlaj, R., R.V. Seeniraj, B. Hafner, C. Faber and K. Schwarzer (1999). Improvement of the heat transfer in a phase-change-material storage. Solar Energy 65 (3), 171-180.

Verlaj, R., R.V. Seeniraj, B. Hafner, C. Faber and K. Schwarzer (1997). Experimental analysis and numerical modelling of inward solidification on a finned vertical tube for a latent heat storage unit. Solar Energy 60, 281-290.

Whitakar, S. (1977). Simulation heat, mass and momentum transfer in porous media a theory of drying. Advances in Heat Transfer 13, Academic Press, New York, 119-203.

Zalba, B., J.M. Marin, L.F. Cabeza, H. Mehling (2003). Review on thermal energy storage with phase change materials, heat transfer analysis and applications. Applied Thermal Engineering 26, 251-83. 
N.B. Khedher and S.B. Nasrallah / JAFM, Vol. 3, No. 2, pp. 97-109, 2010.

\section{APPENDIX}

Physical characteristics of porous stock (brick) and air used in the simulation are listed below:

\begin{tabular}{|c|c|}
\hline Material properties & Values used for the computations \\
\hline \multicolumn{2}{|l|}{ Porous medium } \\
\hline Porosity & 0.36 \\
\hline Density of solid matrix & $\rho_{S}=2.6 \times 10^{3}\left(\mathrm{~kg} \mathrm{~m}^{-3}\right)$ \\
\hline Specific heat capacity of solid matrix & $c_{p s}=8.79 \times 10^{2}\left(\mathrm{Jkg}^{-1} \mathrm{~K}^{-1}\right)$ \\
\hline Specific heat capacity of liquid & $c_{p l}=4.22 \times 10^{3}\left(\mathrm{Jkg}^{-1} \mathrm{~K}^{-1}\right)$ \\
\hline Specific heat capacity of vapor & $c_{p v}=1.86 \times 10^{3}\left(\mathrm{Jkg}^{-1} \mathrm{~K}^{-1}\right)$ \\
\hline Liquid dynamic viscosity & $\mu_{l}=6.5 \times 10^{-4}\left(\mathrm{~kg} \mathrm{~m}^{-1} \mathrm{~s}^{-1}\right)$ \\
\hline Vapor dynamic viscosity & $\mu_{v}=1.860 \times 10^{-5}\left(\mathrm{~kg} \mathrm{~m}^{-1} \mathrm{~s}^{-1}\right)$ \\
\hline Intrinsic Liquid permeability & $2.5 \times 10^{-14}\left(\mathrm{~m}^{2}\right)$ \\
\hline Relative Liquid permeability & $k_{l}=X^{* 3}$ with $X^{*}=\frac{X-X_{i r}}{X_{s a t}-X_{i r}}$ with $X_{i r}=0.3$ \\
\hline Relative Gaseous permeability & $k_{r g}=1+\left(2 X^{*}-3\right) X^{* 2}$ \\
\hline Gaseous diffusion & $\begin{array}{c}0.2 \times \mathrm{D}_{\mathrm{v}} \times k_{\mathrm{rg}} \quad \mathrm{D}_{\mathrm{v}}=\text { mass diffusivity of vapor in the air phase } \\
D_{v}=2.26\left(\frac{P_{r e f}}{P}\right)\left(\frac{T}{T_{r e f}}\right)^{1.88}\end{array}$ \\
\hline Capillary pressure & $\begin{array}{l}\qquad P_{c}=\left(\frac{\varepsilon}{K}\right)^{\frac{1}{2}} \sigma J(S) \text { with } \\
J(s)=0.364[1-\exp (-40(1-S))]+0.221(1-S) \\
+\frac{0.005}{S-0.05} \\
\text { and } \sigma(T)=(121.2-0.167 T) 10^{-3}\end{array}$ \\
\hline Vapor pressure & $\begin{array}{c}\left\langle\mathrm{P}_{\mathrm{v}}\right\rangle=\left\langle\mathrm{P}_{\mathrm{vs}}\right\rangle \exp \left[\frac{2 \sigma \mathrm{M}_{\mathrm{v}}}{\mathrm{r} \rho_{1} \mathrm{R}\langle\mathrm{T}\rangle}\right] \text { with } \\
\log _{10}(r)=2.1610^{-2}+43.8 \mathrm{~S}-253.5 \mathrm{~S}^{2}+794.54 S^{3} \\
-1333.7 S^{4}+1111 S^{5}-352.5 S^{6}\end{array}$ \\
\hline Thermal conductivity & $\begin{array}{c}\lambda_{\text {eff }}=\left(\lambda_{g}^{a}\left(\varepsilon-\varepsilon_{l}\right)+\lambda_{l}^{a} \varepsilon_{l}+\lambda_{s}^{a}(1-\varepsilon)\right)^{\frac{1}{a}}\left(\mathrm{Wm}^{-1} \mathrm{~K}^{-1}\right) \\
\text { With } \mathrm{a}=0.25\end{array}$ \\
\hline Working fluid: air & \\
\hline Specific heat capacity & $1006\left(\mathrm{Jkg}^{-1} \mathrm{~K}^{-1}\right)$ \\
\hline Thermal conductivity & $0.026\left(\mathrm{Wm}^{-1} \mathrm{~K}^{-1}\right)$ \\
\hline Density & $1.17\left(\mathrm{~kg} \mathrm{~m}^{-3}\right)$ \\
\hline dynamic viscosity & $1.85 \times 10^{-5}\left(\mathrm{~kg} \mathrm{~m}^{-1} \mathrm{~s}^{-1}\right)$ \\
\hline
\end{tabular}



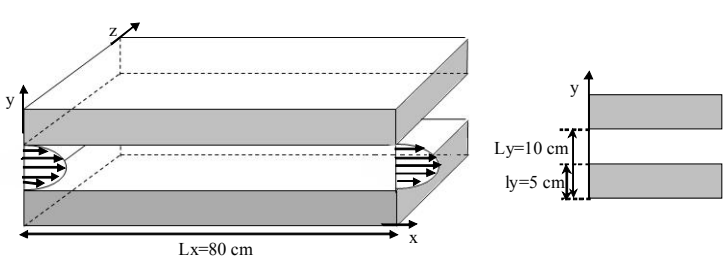

Fig. 1. Geometrical configuration of the problem

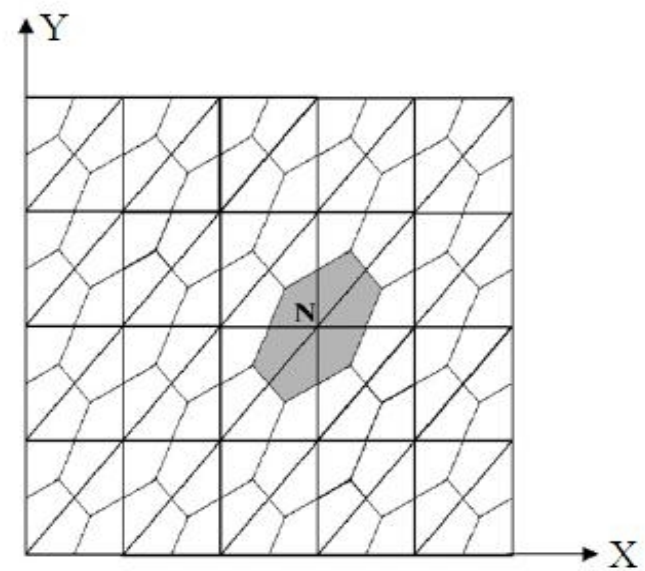

Fig. 2. control volume construction

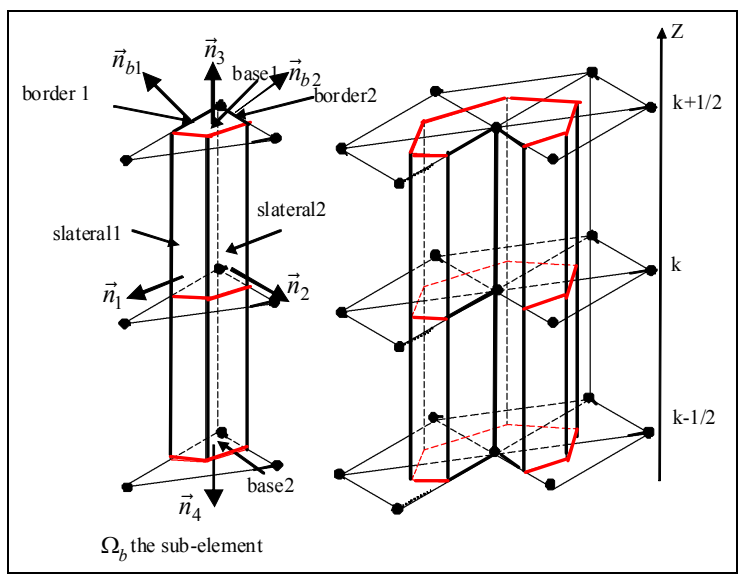

Fig. 3. control volume and sub-volume

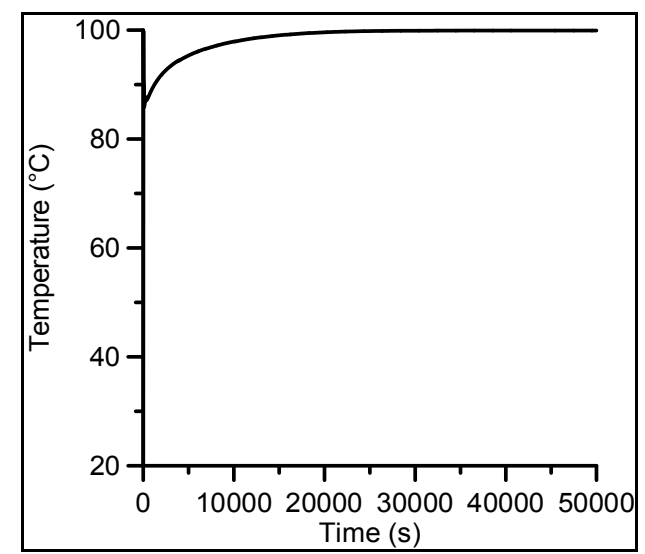

Fig. 4. Transient profile of the mean exiting temperature during the charging period, for $\mathrm{Re}=500$, Tin $=100^{\circ} \mathrm{C}, \mathrm{T}_{0}=20^{\circ} \mathrm{C}$

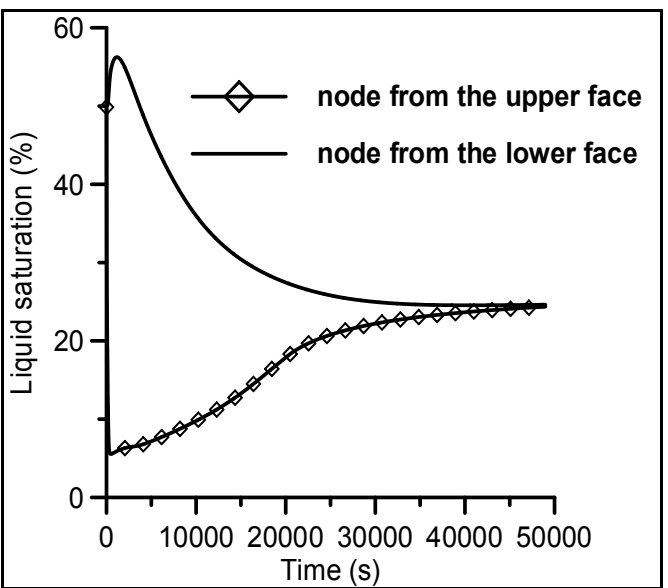

Fig. 5. Transient profile of the liquid saturation for two nodes existing in the porous medium during the charging period, for $\mathrm{Re}=500$, $\mathrm{Tin}=100^{\circ} \mathrm{C}, \mathrm{T}_{0}=20^{\circ} \mathrm{C}$

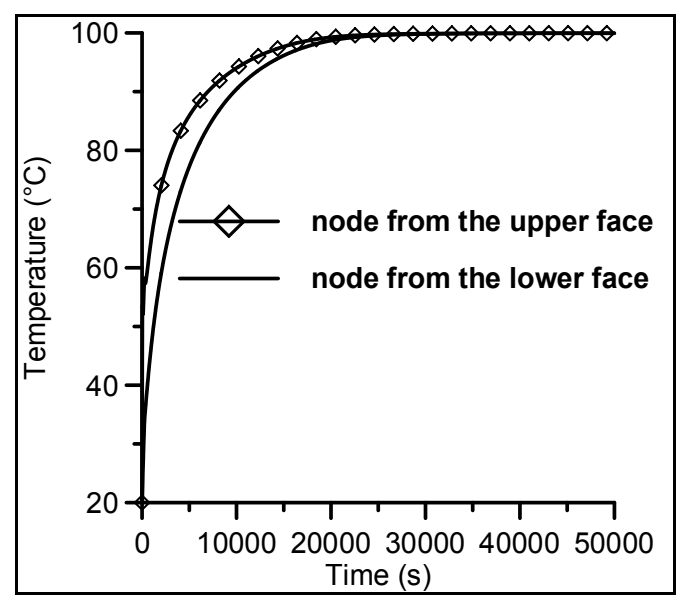

Fig. 6. Transient profile of the temperature for two nodes existing in the porous medium during the charging period, for $\mathrm{Re}=500$, $\operatorname{Tin}=100^{\circ} \mathrm{C}$, $\mathrm{T}_{0}=20^{\circ} \mathrm{C}$

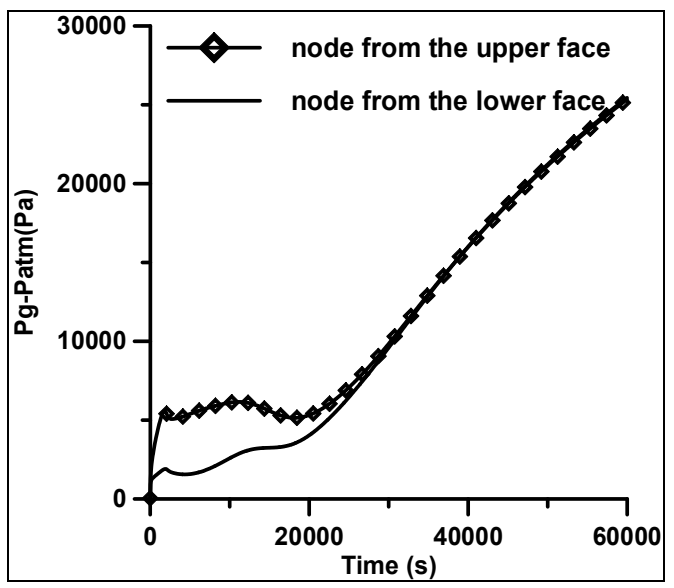

Fig. 7. Transient profile of the gas pressure for two nodes existing in the porous medium during the charging period, for $\operatorname{Re}=500$, $\operatorname{Tin}=100^{\circ} \mathrm{C}$, $\mathrm{T} 0=20^{\circ} \mathrm{C}$ 


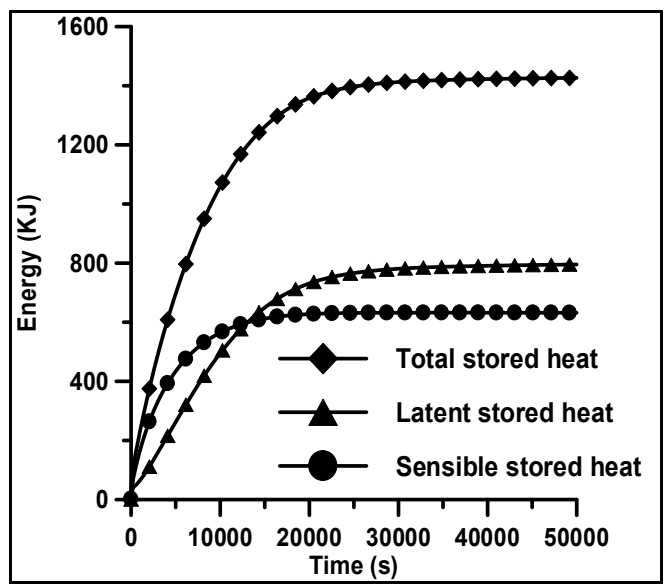

Fig. 8. Transient profile of the exchange heat by air-flow with the porous medium during the charging period, for $\mathrm{Re}=500$, Tin $=100^{\circ} \mathrm{C}$, $\mathrm{T}_{0}=20^{\circ} \mathrm{C}$

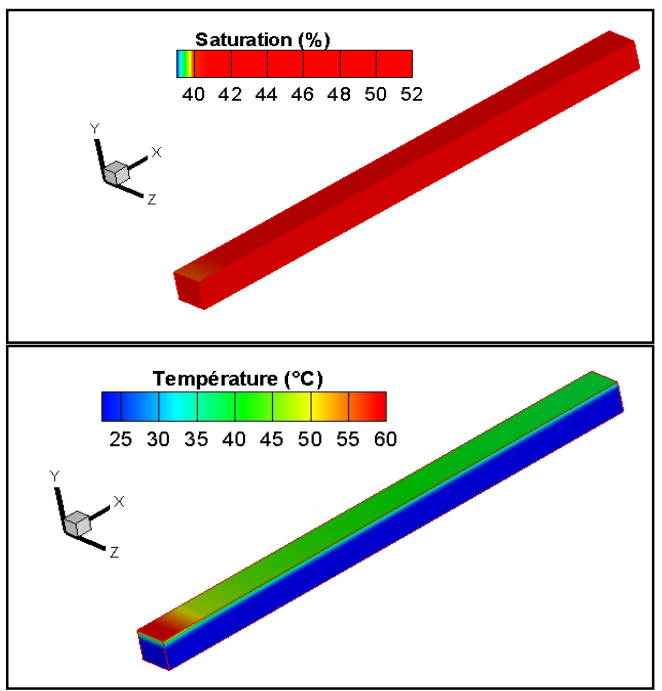

Fig. 9. Temperature and saturation fields after 200s of heat storage

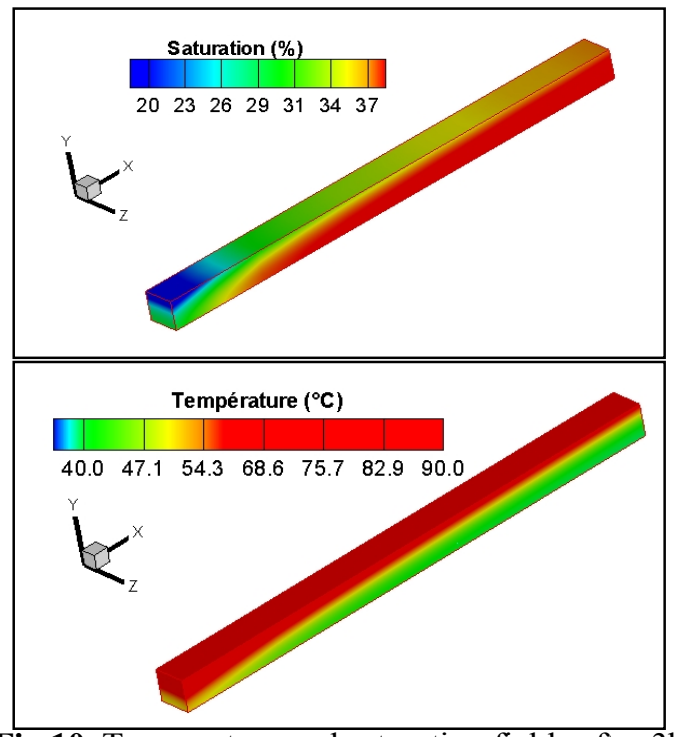

Fig.10. Temperature and saturation fields after $3 \mathrm{~h}$ of heat storage

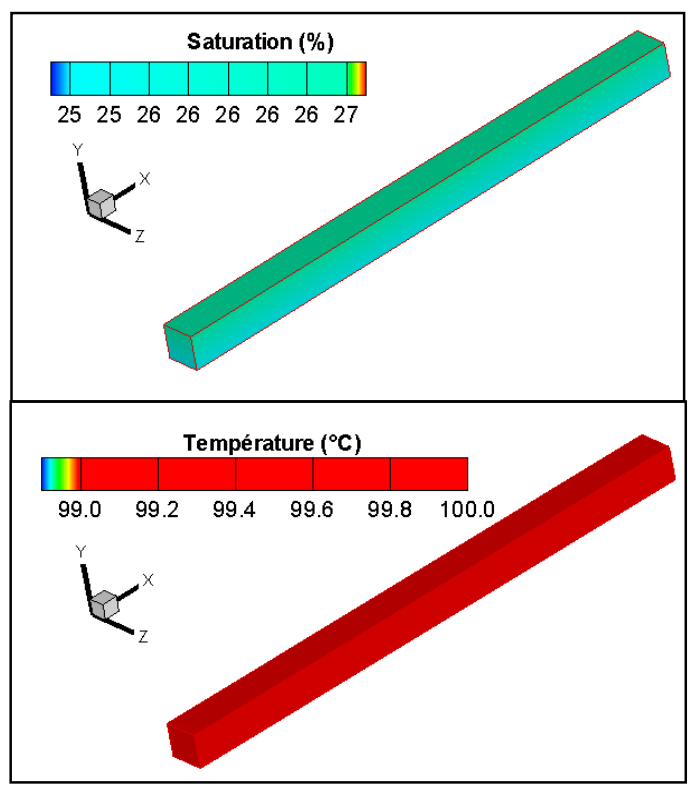

Fig.11. Temperature and saturation fields after $10 \mathrm{~h}$ of heat storage

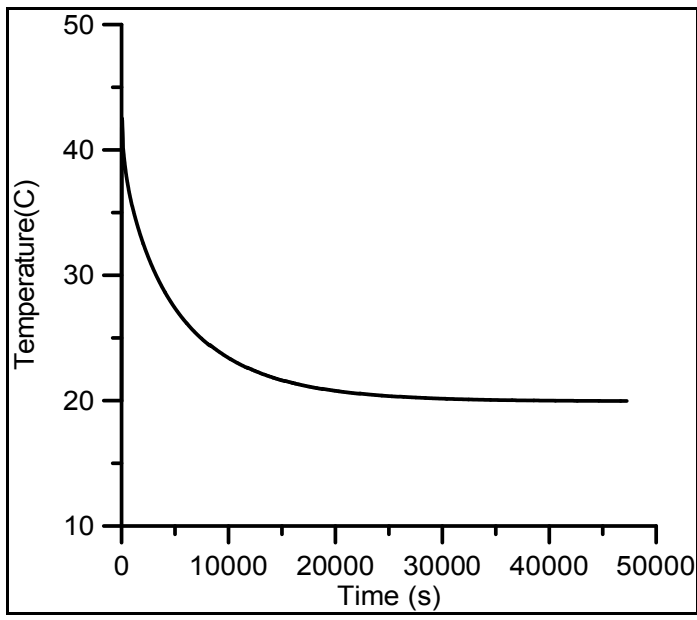

Fig. 12. Transient profile of the mean exiting temperature during the discharging period, for $\mathrm{Re}=500, \operatorname{Tin}=20^{\circ} \mathrm{C}, \mathrm{T}_{0}=100^{\circ} \mathrm{C}$

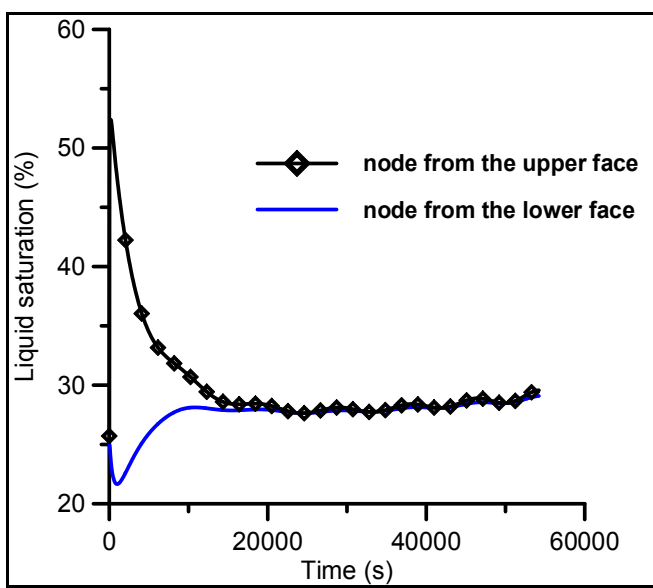

Fig. 13. Transient profile of liquid saturation during the discharging period, for $\mathrm{Re}=500$, $\mathrm{Tin}=20^{\circ} \mathrm{C}, \mathrm{T}_{0}=100^{\circ} \mathrm{C}$ 


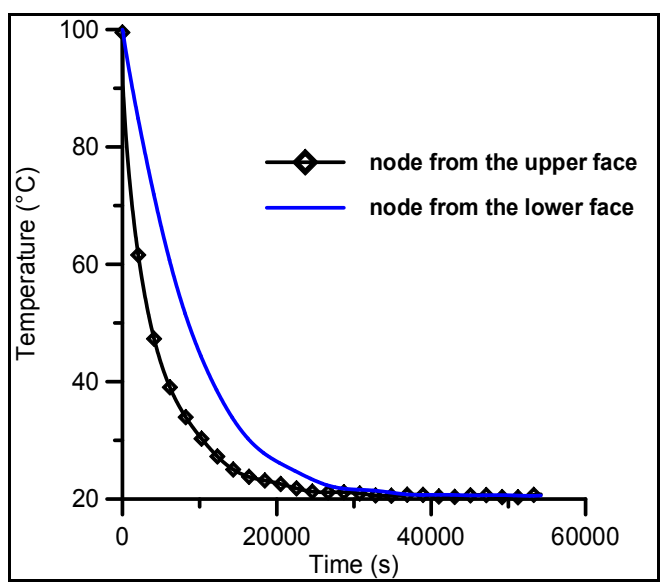

Fig. 14. Transient profile of the temperature for two nodes existing in the porous medium during the discharging period, for $\mathrm{Re}=500, \mathrm{Tin}=20^{\circ} \mathrm{C}$, $\mathrm{T}_{0}=100^{\circ} \mathrm{C}$

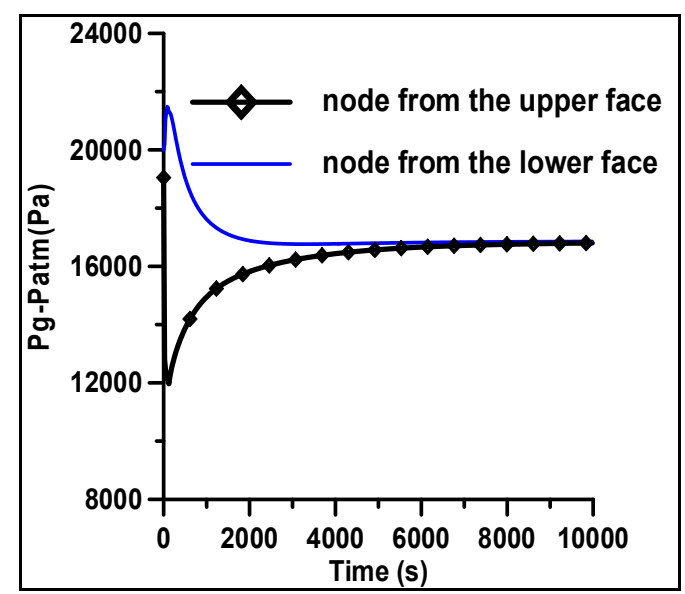

Fig. 15. Transient profile of the gas pressure for two nodes existing in the porous medium during the discharging period, for $\mathrm{Re}=500$, Tin $=20^{\circ} \mathrm{C}$,

$$
\mathrm{T}_{0}=100^{\circ} \mathrm{C}
$$

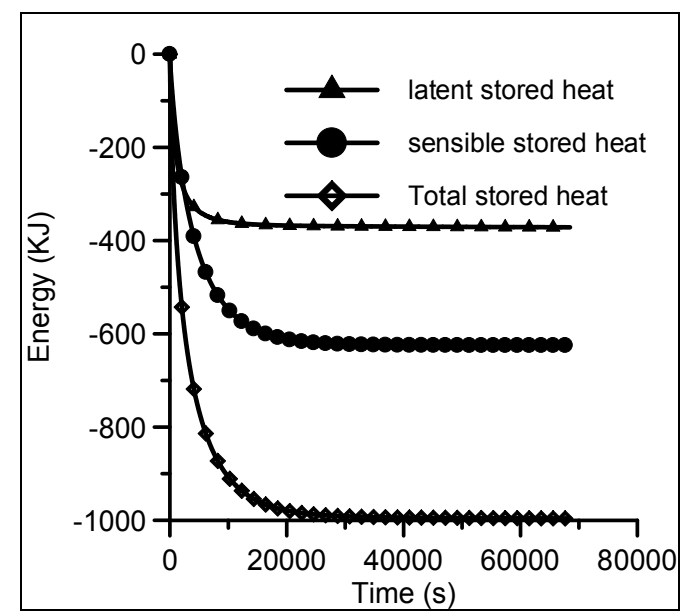

Fig. 16. Transient profile of the heat exchanged by air-flow with the porous medium during the discharging period, for $\mathrm{Re}=500$, $\mathrm{Tin}=20^{\circ} \mathrm{C}$,

$$
\mathrm{T}_{0}=100^{\circ} \mathrm{C}
$$

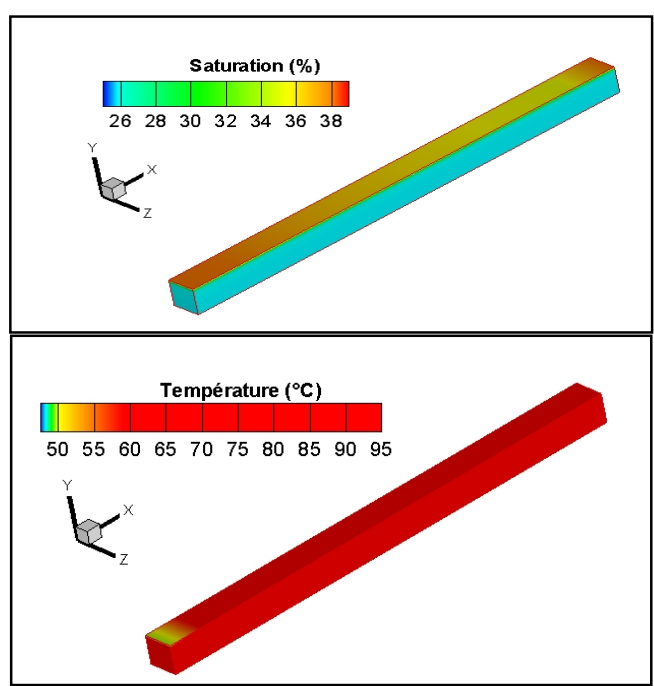

Fig. 17. Temperature and saturation fields after 200s of heat discharging

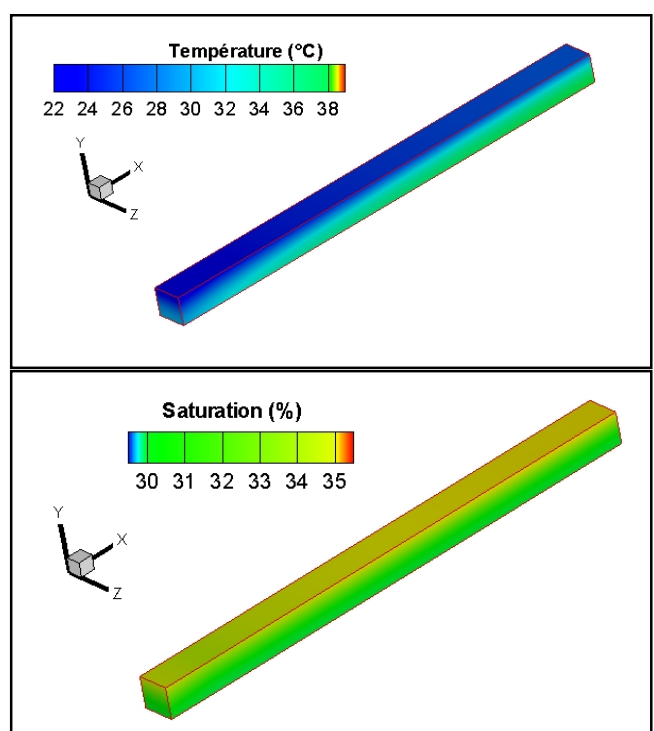

Fig. 18. Temperature and saturation fields after $3 \mathrm{~h}$ of heat discharging

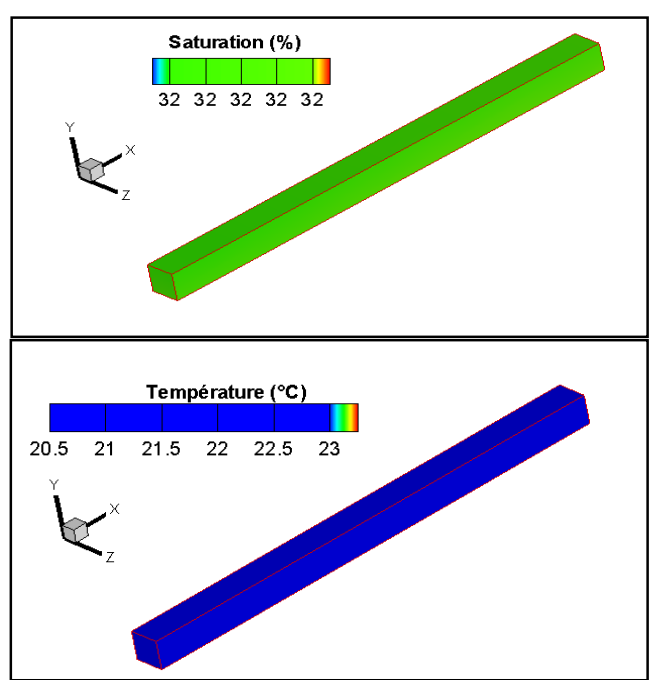

Fig. 19. Temperature and saturation fields after $10 \mathrm{~h}$ of heat discharging 
(a)

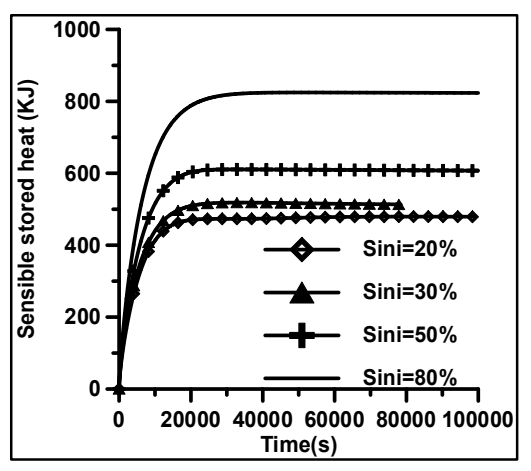

(b)

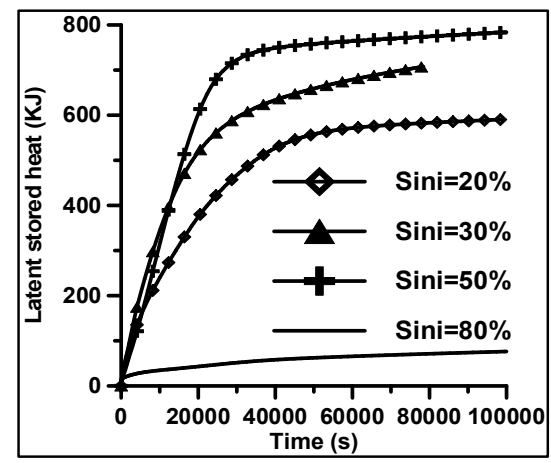

(c)

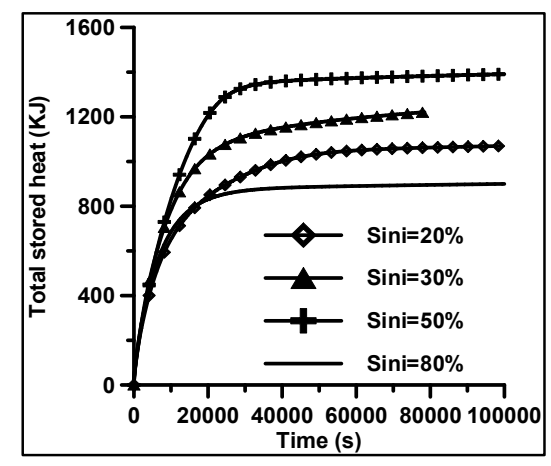

Fig. 20. Influence of initial liquid saturation on the amount of the sensible (a), Latent (b), and Total (c) stored heat during the charging period.

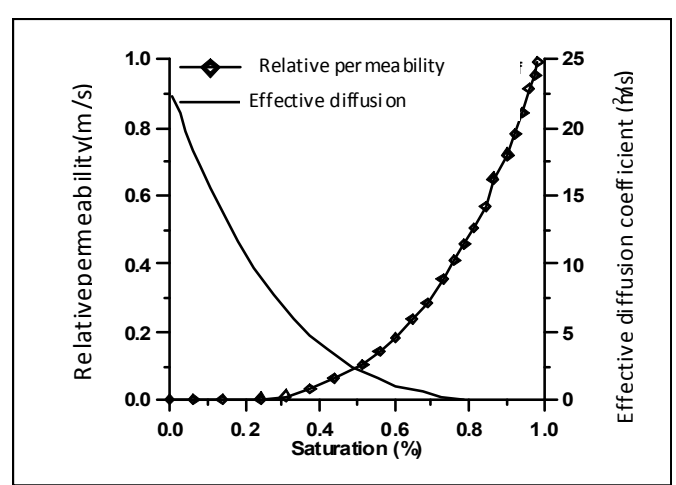

Fig. 22. Evolutions of the effective diffusion coefficient and of the relative permeability in function of the saturation (the case of the brick) (a)

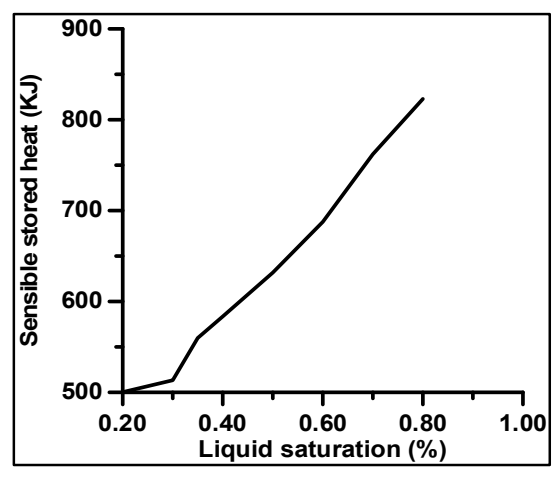

(b)

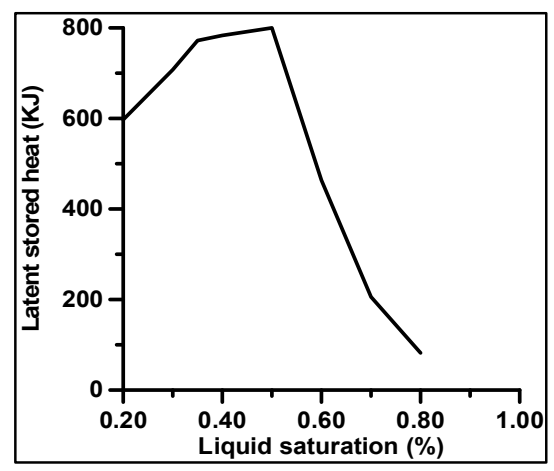

(c)

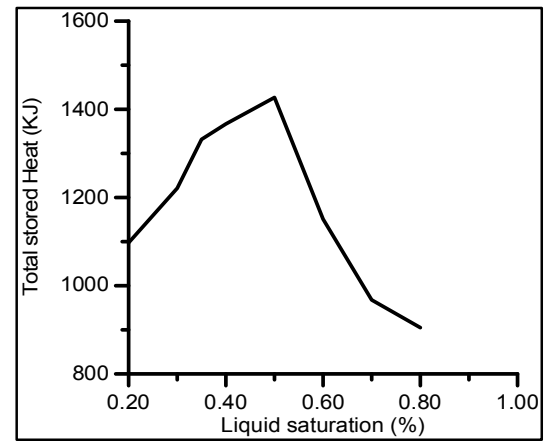

Fig. 21. Influence of initial liquid saturation on the amount of the sensible (a), Latent (b), and Total (c) stored heat during the charging period.

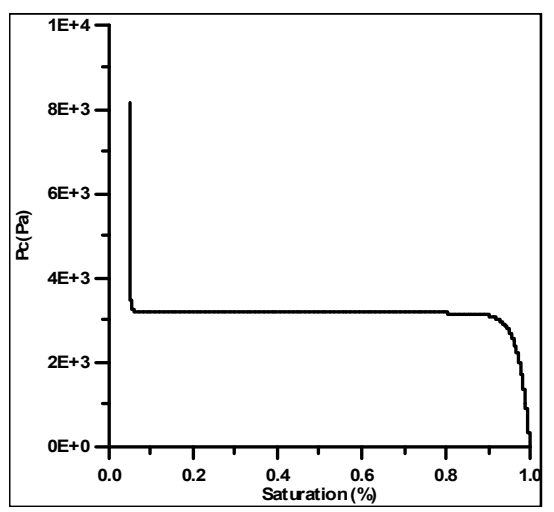

Fig. 23. Evolution of capillary pressure in function of the saturation (the case of the brick) 
(a)

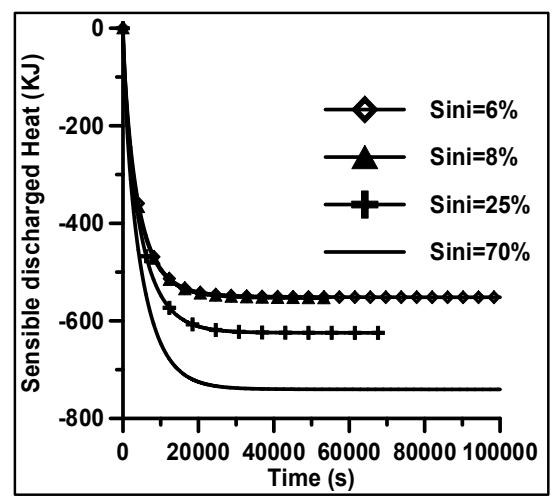

(b)

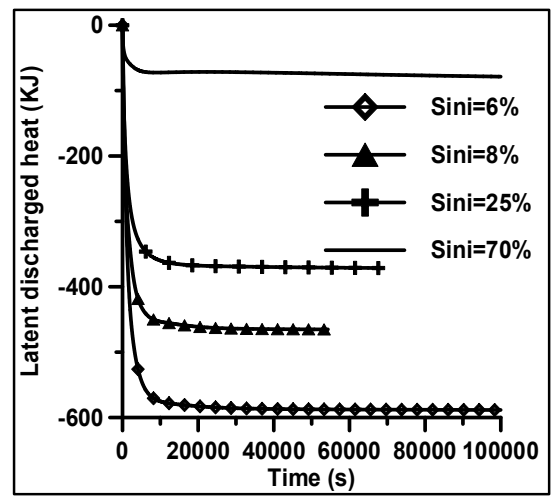

(c)

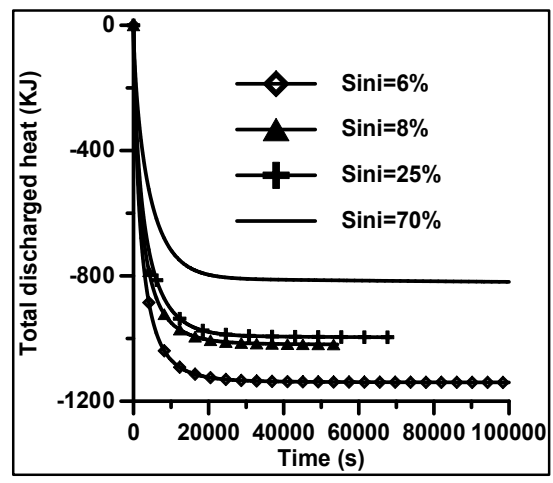

Fig. 24. Influence of initial liquid saturation on the amount of the sensible (a), Latent (b), and Total (c) discharged heat during the discharging period. 